\title{
Territorialidades Ausentes
}

Territorialidades Ausentes

Absent Territorialities

\section{Laura Victoria Franquelli}

Universidad Nacional del Comahue - Argentina franquellilaura@yahoo.com.ar

Como citar este artigo:

FRANQUELLI, Laura Victoria. Territorialidades Ausentes. Revista Latino Americana de Geografia e Gênero, v. 12, n. 1, p. 264-278, 2021. ISSN 21772886.
Disponível em:

http://www.revistas2.uepg.br/index.php/rlagg 


\title{
Territorialidades Ausentes
}

\author{
Territorialidades Ausentes
}

Absent Territorialities

\section{Resumen}

Desde la perspectiva de la sociología de las ausencias, las epistemologías transfeministas y las geografías de género, se intenta comprender los vacíos que rodean las identidades masculinas transgénero. Ausencias teóricas en los estudios de la creciente Geografía de Género, ausencias de identificación transmasculina en los colectivos LGTTTBQ+ y ausencias de apropiación y construcción de territorialidades trans. Se toma en este trabajo la noción de performatividad de género y se aplica a la construcción social del espacio cis-heteronormativo. Se observa en el espacio una permanente performativización de las ausencias, una afirmación permanente de la no existencia de sujetes trans en algunos territorios.

Palabras-Clave: Territorio; Transgénero; Performatividad; Ausencias; Cisheteronormatividad.

\section{Resumo}

Desde a perspectiva da sociologia das ausências, as epistemologías transfeministas e as geografias de gênero, tentamos compreender os vazios que rodeiam as identidades masculinas transgênero. Ausências teóricas nos estúdios da crescente Geografia de Gênero, ausências de identificação transmasculina nos coletivos LGTTTBQ+ e ausências de apropriação e construção de territorialidades trans. Tomamos neste trabalho a noção de "performatividad" de gênero e se aplica na construção social do espaço cis-heteronormativo, tomando como corte territorial localidades da província de Neuquén, Patagônia Argentina. Observa-se no espaço uma permanente "performativización" das ausências, uma afirmação permanente da não existência de sujetes trans em alguns territórios.

Palavras-Chave: Territorio; $\quad$ Transgênero; Performatividade; Ausências; Cisheteronormatividade.

\section{Abstract}

From the perspective of the sociology of the absences, transfeminist epistemologies and gender geographies, we seek to understand the voids that surround transgender male identities. Theoretical absence in the studies of the growing Gender Geography, absence of trans masculine identification in lgtttbq + collectives and absence of appropriation and construction of trans territorialities. This article takes the notion of gender performativity and applies to the social construction of the cis-heteronormative space. A permanent "performativity" of the absences is observed in this space, that is, a permanent affirmation of non-existence of trans subjects in some territories.

Keywords: Territory; Transgender; Performativity; Absences; Cis-heteronormativity. 
La invisibilidad - la no - imagen o la no-representación - tiene implicaciones en los cuerpos: ser invisible se siente y vive en la piel. Tristán López.

\section{Introducción}

La Geografía Crítica de los años '60 denuncia una práctica habitual de la disciplina, que parecía perfectamente normal: la descripción de los espacios geográficos como espacios naturalmente desiguales, donde la diferencia socioeconómica plasmada en ellos parece ser un hecho a registrar y no la consecuencia de las desigualdades generadas por el sistema de producción capitalista. Los escritos que suscriben a la mirada crítica de la Geografía parten de esta denuncia para poder desentramar las causas de las desigualdades territoriales: relaciones de poder, relaciones de clase, territorialización del proceso productivo, globalización de los mercados, etc.

Aprendimos de esta corriente que los espacios no son neutros, no son naturales, no existen por sí solos sin lógicas de poder que los atraviesen y los construyan. Este aprendizaje nos lleva a pensar una Geografía activa, que permita cuestionar el orden socio-espacial vigente.

Con esta misma lógica, la Geografía de Género se propone denunciar la aparente naturalidad del espacio, donde a priori nadie podría pensar que tiene un carácter sexo-genérico que lo rija. Para desenmascarar esa neutralidad del espacio, es preciso construir herramientas metodológicas y teóricas nuevas que nos aporten los conceptos que necesitamos.

Las epistemologías transfeministas ${ }^{1}$ se dan a la tarea de desarmar la mirada científica androcéntrica que sólo permite un análisis de la realidad acotado, rígido y objetivo. El desarrollo de otras formas de construir saberes vinculados a la experiencia, a la subjetividad, a la construcción de conceptos nuevos es propio de los feminismos y las teorías queer. La reflexión que propongo encuentra palabras y fuerza en estos saberes y toma la potencia de las ausencias como lo propone Boaventura de Sousa Santos, para transformar en denuncia la aparente neutralidad del espacio.

Este espacio que es presentado como neutral nunca deja ver las huellas de las vidas y cuerpos transgénero, las historias, los recorridos, los destierros que sufren. Esa denuncia, aprendida de las geografías críticas y las epistemologías transfeministas, nos acompaña en la búsqueda de esas territorialidades ausentes.

Las ausencias que se busca visibilizar en este trabajo se dan en distintos ámbitos, con distintas formas de operar: ausencia teórica en las publicaciones sobre Geografía y Género, ausencia de la identidad transgénero masculina en

1 Utilizaré este término que me resulta superador y me permite referirme tanto a las teorías queer como a las feministas. En el libro Transfeminismos, epistemes, fricciones y flujos, se define del siguiente modo: "Este 'nuevo' vocablo materializa la necesidad política de hacerse cargo de la multiplicidad del sujeto feminista. Pero también es un término que quiere situar al feminismo como un conjunto de prácticas y teorías en movimiento que dan cuenta de una pluralidad de opresiones y situaciones, mostrando así la complejidad de los nuevos retos a los que debe enfrentarse y la necesidad de una resistencia conjunta en torno al género y la sexualidad." 
los colectivos LGTTTBIQ+, ausencia en los territorios de les sujetes transgénero. Este no es un relevamiento exhaustivo ni pretende ordenar/jerarquizar las ausencias, sólo denunciarlas para poder recuperar lo que se pierde en esa expulsión y ocultamiento.

\section{¿Quiénes construyen los territorios?}

En los últimos años, los estudios geográficos latinoamericanos se han volcado al estudio de los territorios, sus construcciones y sus luchas. La comunidad geográfica ha avanzado en su comprensión; en la carga política que poseen; en desentramar las relaciones de poder que los configuran; en sus formas de apropiación que pueden ser superpuestas, dinámicas, resistidas o aceptadas. Pero, sin dudas, en los últimos años, se comprende la construcción del territorio como resultado de las relaciones sociales que lo habitan y disputan. Así como también se comprende cómo los territorios atraviesan los comportamientos de los grupos sociales. Entrelazados en una relación dialéctica, permanente, conflictiva e histórica, sociedad y territorios no deberían considerarse nunca más como conceptos asépticos, disociados uno de otro. Esta acción de construcción, cuando responde a lógicas específicas de grupos que se apropian del lugar que habitan, se considera territorialidad. Estas varían en escala y durabilidad: una empresa multinacional construye territorialidad en distintos puntos del mundo, una feria de productores en un barrio construye territorialidad en una pequeña ciudad, entre muchos ejemplos posibles.

Desde esta perspectiva, entendemos que les sujetes son atravesades por los territorios que habitan, que construyen y les construyen. Como expresa Alejandro Benedetti:

El territorio no es un soporte material, algo con existencia previa a las relaciones sociales, sobre el que se desarrollan los procesos: el territorio mismo es un proceso, constitutivo del entramado de relaciones sociales. Es la sociedad, en su devenir, la que construye no "el" sino "los" territorios. Cotidianamente, lidiamos con infinidad de territorialidades, superpuestas y de diferentes escalas. (BENEDETTI, 2009, p. 51.)

Las ausencias construidas sobre los cuerpos trans en los territorios dejan trunca esa posibilidad de construir territorialidades propias. Al ser excluides no pueden llevar adelante el proceso de apropiación, identificación y el sentido de pertenencia con los territorios de origen.

La comprensión del territorio como construcción social puede abordarse desde múltiples enfoques y es tomado por distintas disciplinas tales como la Historia, la Sociología, la Antropología, la Economía, etc. Pero es bastante reciente desde la perspectiva de género. Contemplando siempre al territorio como "constitutivo del entramado de relaciones sociales", avanzamos en la comprensión de un territorio marcado por los géneros y una construcción de los géneros situada en territorio.

Los aportes de Ana Sabaté, a pesar de posicionarse desde el binarismo hombre-mujer, ayudan a introducir estas discusiones en la ciencia geográfica: 
La práctica totalidad de diferencias entre hombres y mujeres por lo que refiere a funciones, división del trabajo y relaciones de poder derivan de las diferencias del género (construcción social) y no del sexo (constitución biológica); puesto que las mencionadas variables (funciones, división del trabajo, acceso a recursos) varían considerablemente en el espacio y en el tiempo, la construcción social del género también está sujeta a importantes variaciones territoriales. (SABATÉ, 1995, p. 63)

Comprender las territorialidades desde las epistemologías transfeministas nos habilita a denunciar las ausencias de las diversidades sexo-genéricas en los territorios y en las producciones teóricas y a superar el binarismo hombremujer instalado en los estudios de Geografía de Género.

Son las teorías transfeministas las que elaboran un vocabulario amplio que permite nombrar los vacíos históricos construidos minuciosamente por una ciencia hegemónica, androcéntrica y heterosexual. Hoy escribimos desde la diversidad, hoy nos nombramos cis, trans, gais, lesbianas, héteros, intersex, queers.

Sin embargo, la denuncia de la cis-hétero normatividad recae siempre sobre el sistema, sobre las relaciones sociales, sobre el orden jurídico, sobre las relaciones de producción y muy pocas veces sobre el espacio.

El geógrafo Francisco Fernández Romero aborda esta problemática y su trabajo constituye un avance significativo en los estudios geográficos:

Si solamente estudiáramos el momento de la exclusión espacial de personas trans -por ejemplo, a través del concepto de "transfobia"-, correríamos el peligro de ignorar el proceso de producción del espacio; es decir, podríamos dar por sentado que todo espacio es originalmente o esencialmente cis y que solamente surge un problema cuando alguna persona trans aparece para perturbar ese espacio que ya estaba "naturalmente ahí". En cambio, sostenemos que interesa preguntarse por el rol del cisexismo en la producción del espacio: ¿qué supuestos en torno al cuerpo, al género, y al vínculo entre ambos subyace a la producción espacial? (ROMERO, 2019, p. 25)

En este planteo inicial, el autor rompe la lógica con que abordamos los estudios espaciales habitualmente y propone cuestionar la supuesta naturalidad y neutralidad de los espacios, a la vez que devela otra forma de opresión, poco abordada por los estudios sociales: el cisexismo. "El cisexismo es un eje de opresión análogo al sexismo, al racismo, al heterosexismo, etc.; como cualquier eje de opresión, se vincula e intersecta con los demás, aunque posee especificidades que lo diferencian." (ROMERO, 2019, p. 24)

Comprender la categoría "cisexismo" implica comprender la realidad de las personas transgénero quienes fueron históricamente marginadas aún dentro del colectivo de las disidencias, lo que constituye otra capa de opresión en un sistema mucho más amplio.

Los cuerpos transgénero formalizan una ruptura visible de la normada relación entre sexo biológico, género, identidad y deseo. Esta ruptura implica desafiar las reglas que regulan las sociedades, las leyes, los modos de 
producción y los espacios. Históricamente fueron condenados, expulsados, patologizados, ocultados. Ser trans es un presunto no ser, es una ausencia en la humanidad, no están en las escuelas, en los trabajos, en los hospitales, en los territorios.

\section{Transmasculinidades}

Se teje desde estas ausencias la organización, las resistencias, las luchas, y se construye una "nostredad", como lo expresa Marlene Wayar en su teorización sobre la experiencia travesti.

La construcción de la otredad es constitutiva del ser: somos negando ser esa otredad. El que construye una otredad negativizada, amenazante es el modo patriarcal. A las 'travas', el patriarcado nos quiere muertas y, en el mejor de los casos, nos descarta y allí quedamos, en plenas relaciones de poder, apoyadas en los géneros para que un país entero nos abuse sexualmente y cuando ya crecemos y tenemos edad punitiva, confinadas a campos a cielo abierto con lógicas concentracionarias. El feminismo como doctrina exige una ética. No puede quien lo abraza ser constructora de otredades en los términos patriarcales. (WAYAR, 2018, p. 3)

Marlene Wayar, Susy Shock, Lohana Berkins, Claudia Pía Baudracco², son los nombres que afloran si pensamos la lucha travesti/trans en Argentina. Mujeres enormes que dieron su vida, su cuerpo, su alma para hacer del mundo un lugar más justo, para les trans y para todes. Son mujeres trans las referentas y las creadoras de las primeras organizaciones: Transexuales por el Derecho a la Vida y a la Identidad, Travestis Unidas, La Asociación de Travestis Argentinas, todas conformadas al inicio de la década del '90 con el objetivo de protegerse $\mathrm{y}$ organizarse frente a la persecución $\mathrm{y}$ abuso policial $\mathrm{y}$ ser reconocidas como sujetos de derecho.

¿Qué sucedía en aquellas épocas con los hombres trans? Frecuentemente escuchamos la idea de que es más fácil pasar desapercibido siendo hombre trans que mujer trans; como dirían en Chile: se puede "pasar piola". Esta apreciación es un tanto subjetiva, cada masculinidad es diferente.

Lo que está claro es que en nuestro país, al evocar la lucha trans, no afloran en el imaginario de las personas las masculinidades. Se constituye, en la identificación de las identidades disidentes, nuevamente, una ausencia ¿Quiénes son los hombres trans? ¿Cómo están organizados? ¿Qué teorías hablan de ellos? ¿Qué voces los representan? ¿Cómo construyen territorialidades? ¿De qué manera nosotres aumentamos la ausencia al desconocer sus luchas, sus orgas, sus acciones?

La primera vez que escuché sobre un hombre trans fue en una de las

2 Marlene es psicóloga social, activista y directora de "El teje" primer diario travesti/trans argentino, Susy es actriz, escritora, cantante, activista, autora de una frase que nos cobija a muches "no queremos ser más esa humanidad". Lohana fue activista, escritora, asesora política y una de las impulsoras de la ley de identidad de género sancionada en 2012 en Argentina, fallece en 2016. Claudia Pía fue activista travesti/trans, lucho incansablemente por la ley de identidad de género, fallece poco antes de que se sancionara la ley. 
ediciones del reality show "Gran Hermano" del 2011. Allí se anunció con bombos y platillos la gran novedad, la excentricidad de esa temporada: Alejandro Iglesias, un hombre transgénero. Años más tarde, desde mi propia experiencia y militancia, compartiendo espacios con varones trans, me contaron cómo ese participante les cambió la vida, por primera vez se veían reflejados. La importancia de tener un referente, un otro como yo, una identidad política organizada y en lucha marca una diferencia radical en la construcción de la propia subjetividad de les sujetes. No es Alejandro Iglesias ni el primero, ni el único, ni el principal referente de los varones trans, pero su paso por un programa televisivo de gran audiencia y en horario central generó un antes y un después en la concepción de las masculinidades trans..

En un proyecto realizado por Val Flores y Fabi Tron se compilaron relatos de infancias masculinizadas la convocatoria era la siguiente:

Nos importa visibilizar, recuperar y exhumar esas infancias masculinizadas en cuerpos asignados como niñas. No buscamos continuidades ni coherencias, sino relevar señales, huellas, rastros, marcas, cortes, cicatrices, pistas, residuos, vestigios, como un trabajo arqueológico de masculinidades no hegemónicas. (FLORES, TRON, $2012, \mathrm{~s} / \mathrm{p})$

Cuarenta y cuatro relatos componen esta publicación, no todos de hombres trans, algunos de lesbianas, otros de mujeres cis. Lo que está claro es que los rasgos, juegos, atuendos destinados a los varones generaban una frontera en las infancias y cruzarlas era siempre señalado como una infracción.

En casi todos los relatos se repiten los mismos adjetivos: machona y marimacho. Estas dos palabras acompañaron a estas niñeces, en muchos casos hasta su adultez. No se concebía -hasta hace algunos años- una identidad trans masculina como una construcción política, era más un devenir de rasgos poco femeninos o de mujeres lesbianas con formas masculinas. Eran las machonas o los marimachos del barrio, del pueblo. ${ }^{3}$

Esta ausencia de representación política -e incluso de colectivo de identificación- genera mucha angustia en los jóvenes que saben lo que no son, pero no encuentran palabras para lo que son. En una sociedad que exige permanentemente la identificación sexo-genérica, esta ausencia suele ser un estigma muy doloroso.

Con todo, la invisibilización de los hombres trans se da en muchos niveles tanto a lo interno como a lo externo de la comunidad, esta responde a reducciones de nuestra masculinidad, a determinismos e imposiciones sobre nuestra genitalidad y a la ausencia misma de representación de cuerpos disidentes. Dar cuenta de esta es ya un ejercicio de visibilización para empezar a estructurar nuestras identidades a partir del habla, de la imagen, de la historia. La diversidad ha de ser expresada, puesta en canciones, poemas, películas, pinturas. (LÓPEZ, 2018, s/p).

3 El proyecto terminado ya fue publicado y está disponible en internet. Chonguitas es el título del libro, y es una lectura muy recomendada. 
La construcción de un nuevo vocabulario dentro de las teorías transfeministas sirve para visibilizarse, identificarse, encontrarse, nombrarse, porque no nombrar es aportar a construir ausencias. Pero no implica esta identificación un anclaje territorial, una apropiación mediante la acción situada. Las personas trans que habitan los distintos territorios suelen visibilizarse mediante la agrupación, la movilización y la acción política.

El proceso de autoidentificación de los hombres (trans) se ha dado a través de contactos de internet en comunidades virtuales de pares (blogs, sitios web, Orkut, Facebook), ambientes hospitalarios vinculados al proceso de transexualización, universidades y espacios políticos del movimiento LGBT, así como redes personales y contacto con noticias y programas de televisión. (LÓPEZ, 2018, s/p).

Cuando trabajamos temáticas vinculadas a los territorios y buscamos un cruce con las perspectivas de género, encontramos la fuerte presencia de las mujeres cis en defensa de los territorios. Estas luchas son encarnadas frecuentemente por colectivos de mujeres cis que, hermanadas en sus comunidades, han dejado huella en la defensa de los bienes comunes, los saberes ancestrales y los territorios.

Estas experiencias en la región patagónica están encarnadas, principalmente, por los pueblos originarios: la comunidad Mapuce, por ejemplo, ha sido un bastión en cuanto a la defensa comunal de los territorios. En esta defensa, es crucial la participación de las mujeres cis, quienes recientemente difundieron un manifiesto con el nombre "Feminismo Territorial Mapuce". Pero no contemplan las diversidades sexo-genéricas y su vinculación con el territorio.

\section{Performatividad de Géneros, Performatividad de Territorios}

La sociología de las ausencias que propone Boaventura de Sousa Santos invita a denunciar cómo y mediante qué procesos se van construyendo esas ausencias. Pero no con el objetivo de quedarse en la denuncia, sino con la necesidad de recuperar esas voces, eses sujetes, esos saberes, esos cuerpos.

La epistemología de las ausencias, tanto de conocimientos ausentes como de agentes ausentes, nos permite revisar los límites de la representación en las ciencias sociales convencionales: los límites de la representación de la relevancia, de la identificación, de la duración y de la interpretación/evaluación. (SOUSA SANTOS, 2009, p. 92)

Se performativizan las ausencias en los territorios mediante la constante afirmación de la cis-heteronormatividad de los mismos. Quienes vivimos en los espacios no metropolitanos de la Argentina y preguntamos en distintas instituciones sobre las ausencias trans, escuchamos frecuentemente la frase "de eso no hay acá". Esta frase constituye un ejercicio performativo en los términos que lo expresa Butler, ya que termina generando una realidad concreta mediante el uso reiterado del lenguaje. "...la performatividad debe entenderse, no como un 'acto' singular y deliberado, sino, antes bien, como la 
práctica reiterativa y referencial mediante la cual el discurso produce los efectos que nombra". (BUTLER, 2018, p. 18)

Para desarrollar mejor esta idea de performatividad del espacio, se toman como áreas de estudio las localidades con población menor a los 2000 habitantes, asociadas a la ganadería extensiva de subsistencia de la provincia del Neuquén en la Patagonia Argentina. En esta provincia, se realiza desde el año 2018 un trabajo en conjunto con la organización Varones Trans de Neuquén y Río Negro y ATEN (gremio de les trabajadores de la educación). Desde estas dos organizaciones se ofrece un ciclo de charlas llamado "Identidad trans y escuela", totalmente gratuito y destinado a toda la comunidad educativa. En estas charlas, los protagonistas son los varones trans de la organización, con edades de entre 8 y 25 años, algunos escolarizados, otros expulsados del sistema educativo. Las charlas se desarrollan en distintas escuelas de Neuquén capital y en escuelas de pequeñas localidades del llamado interior neuquino, asociadas más a ámbitos rurales que urbanos. Es en estas localidades donde la ausencia es ley, donde se afirma, ante el contacto con estos varones trans: "acá no hay nadie como ustedes".

Dolorosamente, esta afirmación performativiza esos territorios alejados de la capital neuquina, asociados la ruralidad, esa afirmación construye una realidad: no hay niños, jóvenes $u$ hombres trans en ellos. Poco a poco, aparecen los relatos de esas ausencias, poco a poco se descubre dónde están esas identidades.

El acento de las charlas está puesto en visibilizar y dar a conocer las diversas identidades sexo-genéricas para que dejen de ser un vacío. Se observa en estos viajes la rigidez de les adultes, la desinformación y el miedo de quienes están en permanente contacto con les jóvenes (docentes en su mayoría) y no tienen los elementos para abordar las disidencias, lo no binario, lo no hétero. Si no lo entiendo, no lo nombro; si no lo nombro no existe; si no existe no puedo vincularme con quienes, estando delante de mí, no están. Este vacío se alimenta en las aulas, en las familias, en las plazas y se agiganta convirtiéndose en expulsión, rechazo, dolor; ese vacío se llena con información.

En el año 2006, se promulga la ley de Educación Sexual Integral en Argentina, lo que genera un gran entusiasmo entre algunos sectores de la comunidad que veían esta ley como una necesidad imperiosa para transformar la realidad. La ley promueve una mirada integral sobre la sexualidad y el respeto por la diversidad. Con el devenir de los años, se comprobó tristemente el bajo impacto y aplicación de la ley en los sistemas educativos.

Seis años más tarde, en 2012, se sanciona la Ley de Identidad de Género, que marca un antes y un después para las personas transgénero y es un precedente para América Latina y el mundo. La ley les otorga un documento de identidad que refleja el género autopercibido y el nombre de la persona trans, así como la cobertura total de tratamiento de readecuación corporal, tanto en clínicas privadas como en hospitales públicos. Esto mejora la posibilidad de acceso a instituciones educativas, salud y trabajo. Es, por primera vez en la historia, el derecho a ser.

La diferencia de seis años entre la Ley de Educación Sexual Integral y la Ley de Identidad de Género puede ser la causa del bajo impacto de la primera. 
Si bien la ESI propone una mirada integral y busca ampliar la concepción desde los primeros años de educación formal respecto a la diversidad (entre otros objetivos) no deja de reproducir algunos estereotipos binarios $\mathrm{y}$ heteronormados. El desfasaje entre una ley y otra, produce una suerte de "empalme" en el que se pierde la potencia que podrían haber tenido si se hubieran abordado holísticamente.

Al pasar a ser parte de la ciudadanía por primera vez, se conquistan derechos históricamente vulnerados: el acceso a la salud integral, más allá de la adecuación corporal, derecho a circular libremente sin ser detenides, etc. Como sucede en algunos casos, la ley llega antes que el cambio social. Nuestro país avanzó firmemente en la conquista de derechos de distintos colectivos históricamente excluidos, pero en ocasiones los derechos de algunes son un problema para otres.

Hoy, en Neuquén capital, es posible acceder al tratamiento hormonal y a las cirugías para modificar el cuerpo biológico, no sin dificultades. Hay un solo médico que realiza las intervenciones quirúrgicas para el cambio de sexo, que atiende en salud pública y privada. Quienes tienen obra social logran acceder relativamente rápido a la consulta; quienes no, registran demoras de hasta 2 o 3 años.

Todo este proceso llevó tiempo y esfuerzo en la ciudad más grande de la Patagonia, donde de a poco se fue logrando afianzar la ley y hacerla cumplir. Todas las veces, con lucha previa, acompañamiento institucional, reuniones, discusiones. En las localidades con población dispersa lejanas a la capital, nada de esto permeó. La falta de difusión hace que ese derecho adquirido se desdibuje, porque como ya mencionamos antes, lo que no se nombra no existe, la ley que no se conoce no se cumple.

Las luchas incansables del colectivo travesti/trans crearon hitos en nuestro país, desarrollando leyes únicas en el mundo, pero que no se traducen en conquista real de derechos, en cambios en la percepción de la sociedad sobre cuerpos que no les son inteligibles. No logran estas leyes revertir las ausencias.

Una de las localidades visitadas por la organización Varones Trans de Río Negro y Neuquén fue Tricao Malal, un pueblo neuquino con 800 habitantes. Esta comunidad, azotada por altos niveles de suicidio entre jóvenes, convocó a distintas organizaciones gubernamentales y no gubernamentales para poner un alto a la desesperante cifra de nueve suicidios con muy poca diferencia de tiempo entre sí.

El caso más reciente al momento de la charla entre comunidad y organismos era el de un joven de 20 años. El comentario que se repetía entre referentes de la comunidad era "se suicidó porque era homosexual". Esta percepción de la comunidad de la relación causa-efecto que tan naturalizada y difundida estaba, invita a pensar en todas las relaciones que se pueden hacer del mismo modo ante cualquier situación problemática de las "minorías sexuales". Citando a Paul Preciado: "minorías en el sentido deleuziano del término, no en términos estadísticos, sino como un segmento social y políticamente oprimido." (PRECIADO, 2019, p. 70)

Este régimen sexo-genérico que norma las relaciones sociales, estructura también los territorios, los territorios son como resultado de este régimen cisheteronormativos. En este territorio, la disidencia no está contemplada, la 
alternativa es la muerte.

En una nota periodística de un importante medio gráfico local, se bosqueja una radiografía de la situación de este pueblo del norte neuquino, se analiza todo tipo de variables y estadísticas:

En Tricao Malal el promedio de edad entre los que se quitaron la vida es de 32 años y las causas parecen ser tan individuales como diversas. Medida en sus palabras y clara en sus conceptos, la doctora Pasamonte ensaya una explicación: "Hay una realidad muy particular del hombre de campo y es la escasa posibilidad de acceder a cosas que en otras regiones están garantizadas: educación, una salida laboral distinta al campo, otros horizontes, etc. Si bien hay casos que están relacionados con enfermedades, otros tienen que ver con cuestiones como la falta de trabajo y las escasas posibilidades que ofrecen estos lugares". (Diario Río Negro, 14 de noviembre 2004).

Quedan algunas cuestiones muy en claro: 1) se puntualiza sobre "el hombre" en una expresión bastante común en nuestro país, "hombre de campo", como toda una caracterización; 2) se remarcan los rasgos distintivos de las áreas rurales como parte de un contexto de por sí adverso; 3) no se considera, bajo ningún punto de vista, la diversidad sexual en un contexto cishétero normativo.

En diálogo Benjamín Génova fundador y referente de Varones Trans de Neuquén y Río Negro, él reconstruye los relatos que dan cuenta de distintos procesos que generan ausencias en estas localidades: el suicidio, el ocultamiento de la propia identidad y el exilio. Génova, en las distintas charlas desarrolladas, insiste en la necesidad de desarmar esa estructura de pensamiento y ese discurso que naturaliza estas prácticas. La concepción causa-efecto en la frase "se suicidó porque era homosexual" nunca había sido interpelada.

El exilio generalmente se da hacia las grandes ciudades en búsqueda de anonimato, invisibilidad para poder sobrevivir, lugares de contención y encuentro mediante organizaciones que operan en esos lugares.

En los relatos orales de las personas trans en los espacios de militancia compartidos, aparecen palabras que comúnmente trabajamos en las ciencias sociales vinculadas a los sucesos más aberrantes que nos tocó atravesar en América Latina: genocidios, exilios, desaparecidos, entre otros, son una constante en la memoria trans.

El exilio en Argentina fue generado por la última dictadura cívico-militar que persiguió, torturó, asesinó y robó personas. Quienes lograron escapar se refugiaron en otros países para poder sobrevivir. Esta es la historia de muchas personas trans que no ven posible el desarrollo de su vida tal y como es en el lugar de origen y se ven en la obligación de migrar. Y si hablamos de ámbitos rurales, con una población muy reducida, en la que todas las personas se conocen, con un "modo de vida tradicional", con poco acceso a tecnologías y a información, esta migración forzosa es supervivencia.

Uno de los destinos más próximos de este "exilio" es la capital neuquina, que tuvo en los últimos años un desarrollo acelerado al calor de las 
explotaciones hidrocarburíferas. El contraste entre la capital y el resto de las localidades es tan profundo como el de la capital del país y el resto de las provincias. Se reproduce a otra escala la "macrocefalia" de las ciudades capitales latinoamericanas.

La capital neuquina funciona como sede administrativa del yacimiento Vaca Muerta y concentra todas las funciones económicas, administrativas, jurídicas y políticas de dicha actividad. La población actual en la provincia del Neuquén es de 550.745 habitantes, de los cuales 231.198 viven en la ciudad de Neuquén. El contraste entre cantidad de población y acceso a la tecnología y a la información, parece ser la causa de flujos migratorios forzados de muches jóvenes disidentes del "interior" a la capital. Hay, en la dinámica urbana, una esperanza de vivir una vida menos encorsetada que en el ámbito rural.

Es vital comprender el rol del Estado en las desigualdades territoriales, es urgente el desarrollo de políticas públicas que acompañen las luchas de las organizaciones que buscan mejorar la calidad de vida de la población que representan. El impacto de las acciones de los gobiernos provinciales y municipales podría reducir las expulsiones, las violaciones de los derechos elementales e incluso la muerte de sujetes que hoy no pueden ser agentes actives en la construcción de sus propios territorios.

\section{Alcance territorial de las politicas de diversidad de la provincia de Neuquén}

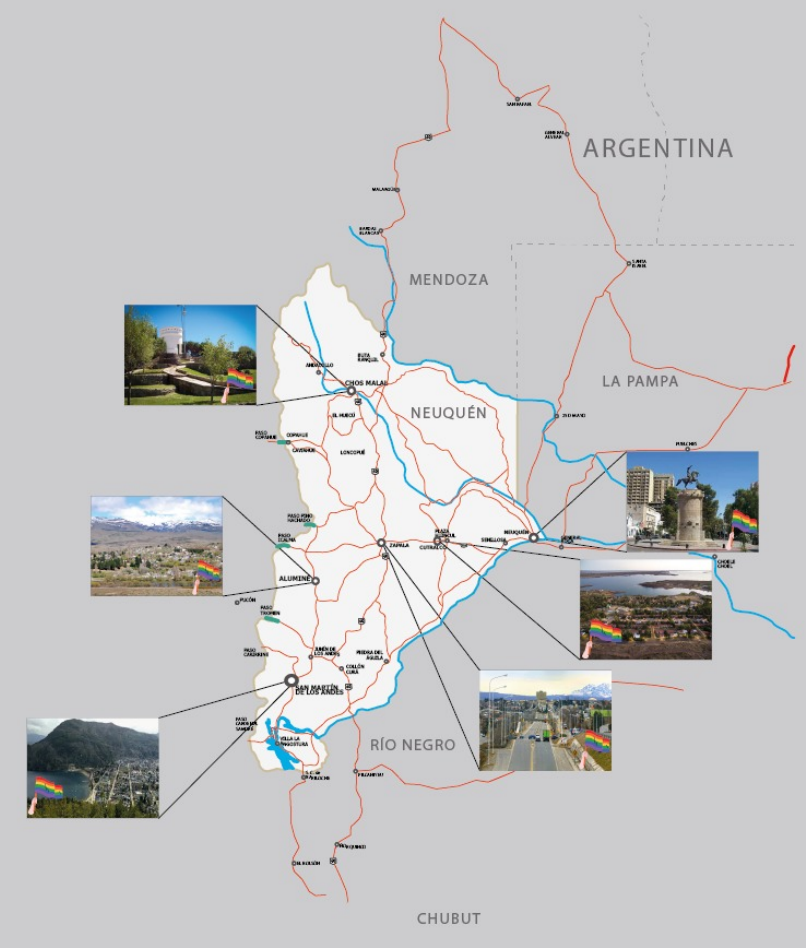
Fuente: Elaboración propia en base a datos de la dirección de diversidad


La provincia de Neuquén creó la Dirección Provincial de Diversidad en el año 2015, bajo la órbita de la Secretaría de Derechos Humanos. Este espacio se aboca a la difusión y promoción de los derechos del colectivo LGTTTBIQ+ y desarrollan actividades en este sentido. El impacto de esta Dirección fue positivo, pero no suficiente, no se ha logrado la cobertura territorial necesaria para revertir los efectos de aislamiento de las localidades con población dispersa. Con el compromiso de muy pocos municipios: Cutral Có, Zapala, Aluminé, Centenario y San Martín de los Andes, comienza el trabajo lento pero necesario de hacer de los asuntos de las "minorías sexuales" un asunto de Estado.La provincia de Neuquén, aunque con algunos avances con respecto a otras, aún tiene una enorme deuda con su ciudadanía. La constitución de una zona de sacrificio ${ }^{4}$ de la mano del yacimiento Vaca Muerta, el impacto de los capitales internacionales vinculados a la actividad hidrocarburífera, los intereses políticos y económicos que dicha actividad generan hacen que la zona rural, asociada a la cría de ganado caprino en muchos casos llevada adelante por crianceros descapitalizados, no figure en la agenda política provincial.

Entonces, volviendo a la idea de cómo se performativizan las ausencias, vemos claramente cómo se imprimen, en el territorio, las reglas del sistema cis hétero patriarcal, que son permanentemente reafirmadas en los espacios llamados "tradicionales" de las localidades vinculadas a actividades rurales. La evocación permanente de una "cultura de campo" asociada a valores conservadores y morales hacen que algunos territorios sean irrespirables para cualquier otra forma de concebir la vida, las sexualidades y el ser.

Hace pocos días, los medios locales difundieron un video y una denuncia de una situación que revolucionó el barrio Nueva Esperanza, situado en la meseta neuquina, en la periferia de la ciudad de Neuquén. El barrio se formó por la ocupación de tierras fiscales por parte de pequeños productores que buscaban tierras que les permitieran desarrollar alguna actividad que intercale el autoabastecimiento y el intercambio. Se configura así un barrio de grandes parcelas con gallinas, algunos chanchos y huertas, sumido en precariedad y falta de acceso a los servicios básicos. La denuncia la realizó el presidente del barrio, quien fue expulsado y relevado de sus funciones al grito de "este es un barrio de gauchos, acá no queremos gays". El presidente del barrio expulsado es hermano del director provincial de diversidad de la provincia, este parentesco es el que impulsa el comentario tan repulsivo, el resto de la disputa es política, no viene al caso. No puedo dejar de analizar esa frase que quedó registrada en videos ampliamente difundidos. ¿Qué es ser gaucho en la Argentina del 2020? ¿Qué valores se supone que invocan? ¿Qué vinculaciones tienen la identidad con el territorio claramente asociado a lo rural aún inserto en la periferia urbana?

4 La organización geopolítica actual implica la configuración de zonas de sacrificio que permitan la reproducción rápida y ampliada del capital. Se consideran estas regiones un costo (ambiental, social, económico) aceptable en el nombre del progreso y el desarrollo de otras regiones del mundo. 


\section{Reflexiones finales}

Los territorios vinculados a actividades rurales, con escasa población dispersa, frecuentemente llamados del "interior" (en contraposición a las grandes ciudades capitales) representan en el imaginario social ciertos hábitos, cierto estilo de vida tradicional que no permite modificaciones y no considera ninguna expresión por fuera de la socialmente establecida y normada. Este vínculo entre territorios con rasgos rurales y la cis heteronormatividad es poco analizado y cuestionado, y sus consecuencias son muchas veces letales.

Quienes nos dedicamos a la educación tenemos un profundo compromiso con la realidad, la vida, las juventudes y los porvenires. Es nuestra obligación aportar a la transformación de estas concepciones que generan opresión, marginación y muerte. Quienes elegimos la Geografía como disciplina no podemos dejar de denunciar el carácter cis hétero normativo del espacio y las consecuentes ausencias que genera. No podemos, quienes pretendemos aportar algo a la construcción de saberes, ignorar la profunda desigualdad que se genera en ámbitos rurales, dispersos y alejados con respecto a los centros urbanos en términos de acceso a derechos, reconocimientos, posibilidades de vida, etc. (tampoco podemos ignorar que esto también sucede en ámbitos urbanos con otras características).

Es urgente disputar el territorio, visibilizar distintas territorialidades, denunciar las ausencias y retomarlas, como propone Santos, para construir un nuevo espacio amplio, complejo, diverso. Un espacio apropiado por todas las personas, por todos los cuerpos, donde nunca más hablemos de inclusión de las diversidades sexuales, ni de las funcionales, ni de las étnicas, ni de las raciales. El Estado es responsable de garantizar los derechos humanos elementales para toda la población.

\section{Referencias}

BENEDETTI, Alejandro. Territorio, concepto clave de la geografía contemporánea. Revista electrónica 12(ntes), v. 4, n. 1, p. 5- 8, 2009.

BUTLER, Judith. Cuerpos que importan: Sobre los límites materiales y discursivos del "sexo". Nueva York: Paidós, 2018.

SOUSA SANTOS, Boaventura de. Una epistemología del sur: la reinvención del conocimiento y la emancipación social. México: Siglo XXI - Clacso, 2009.

FERNÁNDEZ ROMERO, Francisco. Poniendo el cisexismo en el mapa. Una experiencia de cartografía transmasculina. Boletín Geocrítica Latinoamericana $\quad \mathrm{n}^{\circ} 2, \quad 2019 . \quad$ Disponible en: $<$ https://ri.conicet.gov.ar/handle/11336/125413>. Aceso en 17/08/2021.

INADI. Investigaciones por la diversidad. Buenos Aires, 2008.

LÓPEZ, Tristan. Transmasculinidad: cómo se invisibilizan ciertos cuerpos en 
la sociedad. Revista Visibles. Guatemala, 2018. Disponibel en: $<$ https://visibles.gt/author/tlopez/>. Acceso en: 17/08/2021.

PRECIADO, Paul. Un apartamento en Urano: Crónicas del cruce. Barcelona: Anagrama, 2019.

SABATÉ MARTÍNEZ, Ana; RODRÍGUEZ MOYA, Juana; DÍAZ MUÑOZ, Ángeles. Mujeres, espacio y sociedades: Hacia una Geografía del Género. Madrid: Síntesis, 1995.

SOLÁ, Miriam. Transfeminismos: Epistemes, fricciones y flujos. Tafalla: Txalaparta, 2014.

TRON, Fabi; FLORES, Val. Chonguitas: Masculinidades de niñas. Neuquén: La mondonga dark, 2013.

WAYAR, Marlene. No se nace mujer, llega una a serlo. Revista Anfibia, 2018. Disponible en: <http://revistaanfibia.com/ensayo/no-se-nace-mujer-llega-unaa-serlo/>. Acceso en: 17/08/2021.

Artículos periodísticos

El suicidio es la mayor causa de muerte entre los chicos de 15 a 19 años de Río Negro y Neuquén. Disponible en: <https://www.rionegro.com.ar/el-suicidioes-la-mayor-causa-de-muerte-entre-los-chicos-de-15-a-19-anos-de-rio-negroy-neuquen-GWHRN0411142314701/>. Acceso en 17/08/2021.

"Este es un barrio de gauchos; no queremos gays". Disponible en: $<$ https://www.diariamenteneuquen.com.ar/V3.0/2020/08/05/este-es-un-barriode-gauchos-no-queremos-gays/>. Acceso en: 17/08/2021.

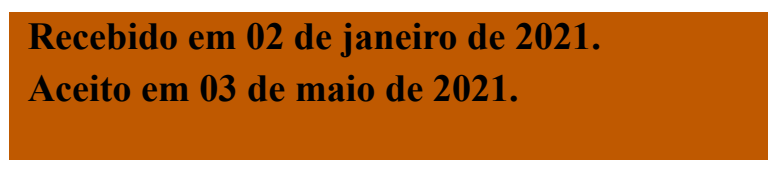

